\title{
THERAPEUTIC HORTICULTURE: INFLUENCING PSYCHOLOGICAL RESPONSES OF SURGICAL PATIENTS AND THEIR ENVIRONMENTAL ASSESSMENT SCALE
}

\author{
Muhammad Ali Khan ${ }^{1, \ddagger}$, Noor ul amin 2,*, $\neq$ Imran Ahmad², Muhammad Sajid², Ibadullah Jan', \\ Abdul Mateen Khattak ${ }^{2}$, Juniad Khan ${ }^{3}$, Mehboob Alam², W.M. Bhutta, Humaira Wasila ${ }^{2}$ and \\ Sikandar Hayat ${ }^{2}$ \\ ${ }^{1}$ Department of Agriculture, Abdul Wali Khan University Mardan, Khyber Pakhtoonkhwa, Pakistan; \\ ${ }^{2}$ Department of Horticulture, Khyber Pukhtookhwa Agricultural University, Peshawar, Pakistan; \\ ${ }^{3}$ Department of Agriculture, University of Swabi, Khyber Pakhtoonkhwa, Pakistan. \\ "Corresponding author's e-mail: drnoorulamin@yahoo.com \\ $\neq$ The authors contributed equally.
}

\begin{abstract}
Therapeutic impact of foliage plants and flower arrangements were evaluated on the post-operative recovery of surgical patients in hospital wards. A total of 270 surgical patients were randomly assigned to two hospital wards with plants and without plants representing ward A and ward B, respectively, making a lot of one hundred and thirty five patients in each comparing ward. Data collected includes parameters for evaluating patients' physiological status, intake of postoperative analgesics, Environmental Assessment Scale, Patient's personal preferences for plants and flowers. More effective health signs were observed for patients admitted in the ward A than those in the ward B. Patients admitted in ward A had significantly fewer (30\%) consumption of strong postoperative analgesic in comparison to ward B (40\%) due to more normal psychological and cognitive responses. More Patients in plant group experienced mild intensity of pain (41.5\%), anxiety (41.5\%), fatigue (49.6\%) as compared to patients in ward B, who experienced severe level of pain, anxiety and fatigue. Patients in ward A were observed with an elevated mood and were socially more active and friendly towards other patients and nursing staff, expressing more positive feelings and describe ward atmosphere more calming, soothing and satisfying in contrast to patients in control group i.e., ward B. Additionally, most of the patients (45\%) in ward A preferred cut flowers, especially red color roses over the green and variegated foliage plants. Furthermore, small group discussion and focal interviews with nurses and doctors affirm that arrangement of plants and flowers in hospitals is an effective, inexpensive and more productive complementary approach in medical field for surgical patients.
\end{abstract}

Keywords: Horticultural therapy, green atmosphere, psychological responses, environment, surgical patients.

\section{INTRODUCTION}

A hospital is thought to be a stressful place for all user groups, including the medical staff, patients, family members, and visitors. Among these, patients are considered to be the most vulnerable segment at the hospital as they are consistently subjected to stresses, trauma, physical pain, health discomfort and other negative symptoms of illness or treatments as a result their equilibrium is disrupted (Rodin and Voshart, 1986). Additionally, patients also have to deal with some other stresses such as worries about their illness, fear of medical procedures, and lack of familiarity with medical personnel, pressure of sterile hospital environment and hospital equipment (Carpmen and Grant, 1993). All these major and minor stresses are linked with variety of emotional, psychological and physical health problems. Stresses require energy and as a result prolonged stress contributes to fatigue of human mind (Aistars, 1987; Irvine et al., 1991). Stresses also results in a number of medical complications like it weakens the body's immune system, increase susceptibility to infectious disease and delay wound repair thus resulting in a slower and more complicated postoperative recovery (Marucha et al., 1998; Padgett et al., 1998). Studies show that greater stress and trauma is associated with surgery patients, and they typically experience more severe pain and a slower recovery period. Some of these problems are treated through the use of anesthetics and analgesics, but, if not properly administered, these anesthetics, muscle relaxants, and narcotic drugs can have side effects ranging from vomiting and headaches to drug dependency or even fatality (Abbott and Abbott, 1995; Markland and Hardy, 1993). It is therefore beneficial to patients and care providers to develop approaches that improve the overall patient experience but don't rely on pharmaceuticals (Park and Richard, 2009). Psychological manipulations, such as positive distraction, have been recognized as effective alternative cognitive strategies to cope with pain and stress (Johnson et al., 1998; Lautenbacher et al., 1998). Further Ulrich, (1992) defined a positive distraction as an element that produces positive feelings, effortlessly holds attention and interest, and 
therefore may block or reduce worrisome thoughts and moreover claimed that nature particularly plants and green environment holds a great positive distractional capability in reducing human worrisome and ailments.

Green atmosphere and interaction with nature (plants and flowers) can considerably improve the human senses and sanity by decreasing the stress associated with anxiety, depression, neurotic impairment, and other psychological symptoms (Brown, 2001; Rodin and Voshart, 1986). One of the simple and cost effective ways to improve patients' emotional states and to provide relaxation could be simply providing plants or other natural elements, which provide ample restorative soothing. Human behavior, mood, emotions and deeds are affected by experiences from surroundings. Green environment has a natural soothing and calming effect on human psyche. The nurturing plants and overall green atmosphere not only change people's emotions and feelings, but also positively influence their physiological responses, including brainwave, heart rate, blood pressure, and muscle tension (Wichrowski et al., 2005). A number of other researchers such as Park and Richard, (2009) also observed this impact during examining human health benefits of plants. Close interaction of prison inmates with greenery can positively affects their self-image and social relationships (Lewis, 2004). Psycho-physiological studies in horticultural therapy suggested that a plant environment seems to provide the preferred form of physiologically measurable stress reduction (Chang and Chen, 2005; Liu et al., 2003, 2004). This relaxation occurs remarkably quickly, almost within minutes (Ulrich, 1992). People in a green environment not only showed faster physical recovery from stress, but also improved psychological, emotional and cognitive states (Kaplan, 2001; Cho, 2002). Positive relationships with plants can make people feel that they are fully human beings. Relationships with plants provide a powerful ongoing connection with life and reconnect human being with daily routine life's (Alexandria, 2009). Thus a comprehensive research activity was conducted by providing green atmosphere in form of foliage plants and flower arrangements in order to analyze its impact on the psychological and cognitive response of surgical patients in hospital. The research project was conducted using a properly designed questionnaire for the patients. A wide range of questions were asked from the patients obtaining data regarding the personnel socio-economic status of the patients, including length of hospitalization, analgesics used for postoperative pain control, ratings of patient's psychological traits such as pain intensity, pain distress, anxiety, fatigue, mood, social behavior (PPAF), Environmental assessment scales (EAS), Patients Room satisfactory Questionnaire (PRSQ) and Patients preferences for different ornamental plants and flowers.

\section{MATERIALS AND METHODS}

A therapeutic horticultural related research study was carried out at Hayattabad Medical Complex Peshawar, Pakistan during 2010 in perspective to evaluate the therapeutic impact of foliage plants and flower arrangements on the psychological and cognitive responses of surgical patients. Surgical patients were chosen for the reason that they exhibit greater extent of pain, emotional stress, psychological depression, anxiety, fatigue and longer stay at the hospital. Patients exclude from the study were those who were younger than 20 years or older than 50 , so that there must be general uniformity into the sample and a certain age group be considered under the study. This specification in the age limits will minimize the age influence on the data taken for the parameters and enabling us to concentrate on same age group people under the experiments. Two hundred and seventy surgical patients were randomly assigned to two wards in the same hospital, naming as "ward A", which was decorated with indoor foliage plants and flower arrangements and "ward B" with no foliage plants and flowers representing control, respectively, thus making a lot of one hundred and thirty five patients in each comparing ward. The selected indoor foliage plants and flowers during the course of study are; Cycus Revoluta, Chlorophytum comosum, Syngonium podophyllum, Dracaena deremensis, Brassaia actinophylla, Araucaria beterophylla, Ficus macleilandii "Alii", Ficus benjamina, Asparagus sprigeri, Rhapis excelsa, Chamaedorea Seifrizii, Chamaedora elegans, Epipremnum aureum, Tujja Orientalis, Canna Plant, Rose hybrida cv. Cardinal, Gladiolus, Polianthes tuberosa,jasmine and Marigold. Attractive and eye catching pots and vases were used for displaying foliage plants and flowers in "ward A". Additionally both the hospital wards were completely identical in all aspects like having the same nursing and paramedics' staff and doctors presence, identical ward size and number of windows with natural views of outside landscape, same sunlight duration during daytime, presence of same nursing stuff and doctors except for the presence of plants. Foliage plants were properly arranged around the ward A while cut flowers were displayed in eye catching vases beside the patients on the side table. Selection of foliage plants was accustomed with less water requirement and maintenance. Extreme care was exercised to keep both the wards isolated from each other.

Data collection: Integrated effective approaches' viz., using specific patients' hospital record, personal discussion \& interviews with patients, small group debates among patients $\&$ nurses and also focal interviews with ward doctors were mechanized for collecting the data regarding the under studied psychological and environmental assessment parameters in the presence of foliage plants and flowers arrangements. Patient's personal data was also gathered through discussion with the patients including patients' name, 
sex, age, occupation, qualification and residence. Psychological \& cognitive responses and environmental assessment parameters were collected from each patient of both the comparing wards. Outcome data related to patient's analgesic intakes was extracted from patient charts while data regarding the psychological and emotional status of patients (patient's, pain intensity, anxiety, fatigue, mood and social behavior), environmental assessment scale of patients' and patients' preferences for specific indoor foliage plants and flowers present in wards were collected directly through a preplan verbal discussion with the patients by using properly prepared patients' questionnaire. The data and results were also analyzed and debated in group discussions discussed with nursing staff and focal interviews with ward doctor. The data was statistically analyzed through Statistical Package for Social Studies (SPSS) specifically using chi-square test and presented in a graphically pattern.

Analgesics consumption was classified in three categories on the basis of the type of drug (oral or injection) and whether the drug was narcotic or not;

Weak Analgesics: oral administered medication ( Brufen, Paracitamal).

Moderate Analgesics: Combine usage of oral medication and small amount of drugs through injection (Maloxicam, Piroxicam, Voren inj.)

Strong Analgesics: Included injection of "Tramal" or "Nalbin" only or doses combination with "Voren" doses.

The analgesics used in weak and moderate category were Non-steroidal anti Inflammatory drugs/ Non- opoidal analgesics (NSAID); whereas analgesics used in strong category were "opoid" analgesics (Lippncott, 2004).

\section{RESULTS AND DISCUSSION}

Patient profile: Table 1 describes overall patient's personal information/ data which can signify the personal status and level of patients involved in the current research study. These information not subjected to any further statistical analysis as the aim is to describe the general standings of patients under study.

Physiological responses of patients: Involuntary feelings and emotions in form of patient's pain, anxiety, fatigue, mood, depression and social interaction describes the overall psychological status of a patient. Impact of foliage plants and flowers arrangement on psychological status of patients is evaluated in this section.
Patient's pain intensity and distress: Data regarding patient experiences with regard to pain intensity and distress are shown in Figure 1. Patients considered for the study in both the comparing wards were all subjected to minor surgeries, so the level of pain intensity was high at admittance to the wards. Pain intensity was significantly different $(\mathrm{P} \leq 0.05)$ between the two studied wards; A and B. Patients in ward A which was decorated with indoor foliage plants and flowers arrangement experience less pain intensity and exhibit high pain tolerance as compare to ward B which was not furnished with plants and flowers. According to the Figure 1, high percentage of patients $(41.5 \%)$ in ward A experienced mild pain as compare to that of ward B (25.9\%) while patients experienced moderate pain were $25.9 \%$ and $31.1 \%$ in ward A \& ward B, respectively. However, $32.6 \%$ of patients experienced severe pain intensity in ward $\mathrm{A}$ in comparison to $43.0 \%$ in ward $\mathrm{B}$. Grinde and Patil (2009) suggested that the cheering, pleasant and attention holding, positively distracting properties of plants might keep away a person from focusing on pain and discomfort. A combination of studies have shown that patients, while undergoing painful procedures reported less pain and display a higher pain tolerance when they were exposed to nature scenes with or without sounds (Tse et al., 2002a,b). Another study reported that plants had greater attention holding power and gave greater relief from pain compared to other aesthetic objects such as a designer lamp or an abstract picture (Lohr and Pearsons-Mims, 2000). Diette et al. (2003) concluded with the notion that views of nature may provide relief from pain.

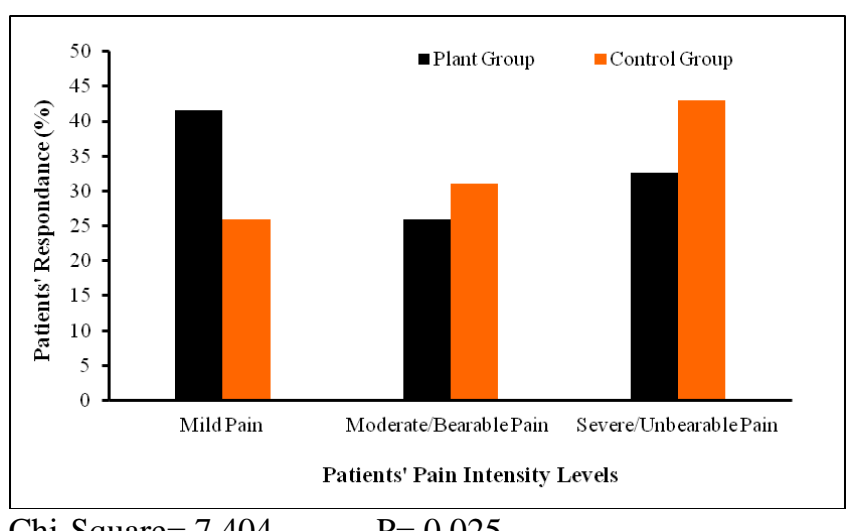

Chi-Square $=7.404 \quad \mathrm{P}=0.025$

Figure 1. Patient pain intensity and distress as influenced by foliage plants and flower arrangement.

Table 1. Patient's profile.

\begin{tabular}{|c|c|c|c|c|c|c|c|}
\hline \multirow[t]{2}{*}{ Cases } & \multicolumn{2}{|c|}{ Gender } & \multirow{3}{*}{$\begin{array}{c}\text { Age } \\
\text { Range } \\
(20-50) \text { years }\end{array}$} & \multicolumn{2}{|c|}{ Education level } & \multicolumn{2}{|c|}{ Income level } \\
\hline & Male & Female & & Secondary School & Higher education & Middle class & Upper class \\
\hline & $190(70)$ & $80(30)$ & & $94(35)$ & $176(65)$ & $204(75)$ & $66(25)$ \\
\hline Total & \multicolumn{2}{|c|}{$270(100)$} & 270 & \multicolumn{2}{|c|}{$270(100)$} & \multicolumn{2}{|c|}{$270(100)$} \\
\hline
\end{tabular}

Values in parenthesis shows percentages 
Patient anxiety intensity levels: A significant $(\mathrm{P} \leq 0.05)$ difference in anxiety level was found among patients in two comparing wards (Fig. 2). Intensity of anxiety was considerably less in patients stayed in ward A which was provided with foliage plants and flower arrangement as compare to patients admitted in ward B with no plants and flowers. It is evident from Figure 2, that higher percentage of patients $(41.5 \%)$ stayed at ward A experienced mild anxiety intensity in comparison to $28.9 \%$ of patients in ward B; Whereas less percentage of patients (27.4\%) in ward A reported severe anxiety intensity as compared to $26.7 \%$ of patients in ward B. Furthermore, patients experienced moderate anxiety intensity were $31.1 \%$ and $26.7 \%$ in ward A and ward B, respectively. It's been evidence from research that while looking at a landscape and green environment, the previously held negative feelings and thoughts, may be about the illness, wounds other worries in a patient's mind are replaced by positive feelings such as interest, cheerfulness and calmness (Hartig et al., 1999). Research studies indicate that nature and green settings reduce stress, promote peace, tranquility, enhanced self-esteem, and sense of mastery of the environment (Lewis, 2004). Nature has been reported to have psychological benefits by reducing stress, improving attention, by having a positive effect on mental restoration (Van den Berg et al., 2007). Likewise, Cackowski and Nasar (2003) observed that green environment and pleasant landscape contributes to higher frustration tolerance and less anxiety status of patients.

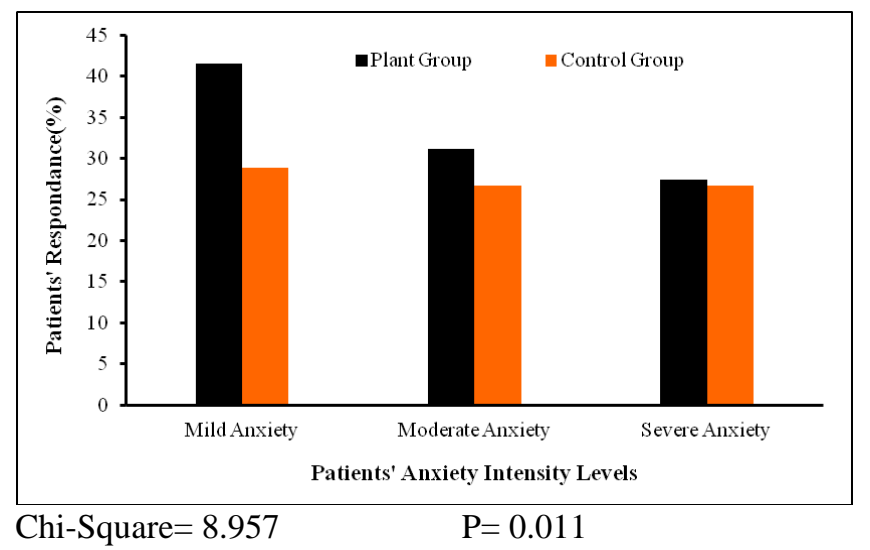

Figure 2. Comparisons of control and plant groups in patient anxiety intensity levels.

Patient fatigue intensity levels: Patients fatigue intensity were significantly $(\mathrm{P} \leq 0.05)$ different for the ward A (plant group) as compared to the ward B (control) (Fig. 3). Patients admitted in ward A reported more mild fatigue and lesser severe fatigue intensity while patients in ward B experienced lesser mild and more severe fatigue intensity. It's been depict from the Figure 3 that at $49.6 \%$ of patients in ward A reported mild fatigue intensity in comparison to $35.6 \%$ in ward B; In addition in ward A few patients (21.5\%) experienced severe fatigue intensity as compared to $31.9 \%$ patients in ward B. Further, patients experienced moderate fatigue intensity were $28.9 \%$ and $32.6 \%$ in ward $\mathrm{A}$ and $\mathrm{B}$, respectively. The restorative effects of natural scenes and green spots attract human attention, resulting in positive changes in emotional states and improve their mental exertion. Presence of indoor plants may help restore attention by relaxing the subjects and help them recover from mental fatigue (Grinde and Patil, 2009). Furthermore, Fjeld (2000) reported that addition of foliage plants and full spectrum lamps in a clinical settings results in a $25 \%$ decrease in typical 'sick building' symptoms, such as fatigue, headache, dry throat and dry or itchy hands of patients. In support, Berto (2005) observed that visual confrontation with pictures of natural landscapes had a restorative effect on mental fatigue in students.

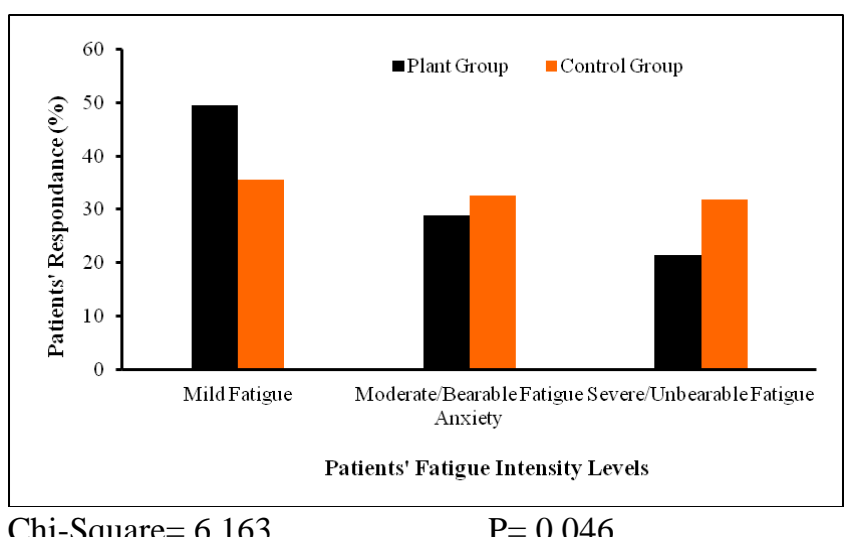

Chi-Square $=6.163 \quad \mathrm{P}=0.046$

Figure 3. Comparisons of patient fatigue intensity levels in plant and control groups.

Patients mood: Statistical analysis describes a significant effect $(\mathrm{P} \leq 0.05)$ of foliage plants and flowers on the mood of patients at ward A. Patients staying in the ward with foliage plants and flowers were found with an elevated mood whereas patients in ward without greenery were observed with a depressed mood. It is evident from Fig. 4 that, a high percentage of patients (39.6\%) was observed with an elevated mood in ward A as compared to ward B (29.6\%). Similarly Patients showing depressed mood were higher $(48.5 \%)$ in ward B in comparison to ward A (37.8\%). An almost equal percentage of patients $(22.6 \%)$ and $(21.9 \%)$ in both the wards responded no change in their mood. Restorative effects of natural scenes attract human attention resulting in positive changes in emotional states (Kuo and Sullivan, 2001b). Furthermore, green environment predominantly green foliage plants increases positive feelings like pleasantness, calmness, peace and harmony in human mind (Ulrich, 2002). Therapeutic horticultural activities improve mood state of patients, suggesting that it may be a useful tool in reducing stress (Wichrowski et al., 2005). Likewise, a recent study of 
a garden in a children's hospital identified mood improvement and restoration from stress as primary benefits for users (Whitehouse et al., 2001)

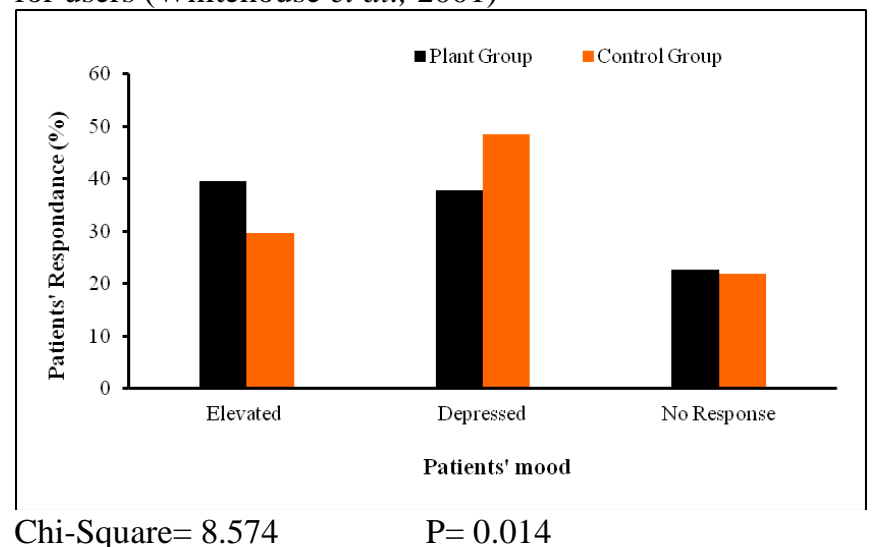

Figure 4. Influence of foliage plants and flowers arrangement on patient's mood.

Social behavior: Figure 5 depicted a significant $(\mathrm{P} \leq 0.05)$ impact of planting arrangements on the social behavior of patients during their stay at hospital. Patients stayed in ward A with provision of foliage plants and flowers were observed with improved social interaction and positive responses to other patients, family members and nursing staff in comparison to patients staying in the absence of greenery. A higher percentage of patients $(52.2 \%)$ were recorded for friendly behavior in plant group as compared to control group (41.5\%); likewise patients find with an indifferent behavior were less in plant group $(47.8 \%)$ in contrast to control group $(58.5 \%)$. An atmosphere with greenery and plants allows the patients to have more opportunity to be relaxed and become more open in discussion about their problems, thus encouraging patients to feel a greater sense of self-worth. Nature creates a positively enhancing perception and improves self-esteem of patients, enabling them to interact with normal world (Hartig, 2004). A study demonstrated that viewing nature, imagining nature, visiting hospital healing garden positively influence healing, alleviate stress, increase well-being and promote participation in social life (Soderback et al., 2004). Moreover, Smith (1998) demonstrated that horticultural (plants) activities in psychiatric units at a hospital are beneficial not only to patients with chronic mental illnesses to improve social skills and self-esteem, but also nursing students and mental health unit staff to build positive relationship with their patients.

Amount of analgesics: Data regarding the quantity of analgesics consumed by patients during hospital stay is presented in Figure 6 elaborating a significantly different $(\mathrm{P} \leq 0.05)$ in rate of analgesics intake for the patients in both comparing wards. Patients in ward A had consumed low quantity of analgesic than patients in ward B. More percentage $(39.3 \%)$ of patients in ward A consumed weak analgesics dose in comparison to patients (28.9\%) in ward B. Patient's percentage using moderate analgesic dose were slightly higher in patients in ward A $(36.3 \%)$ than in ward B $(31.1 \%)$. Similarly, lesser percentage $(30.0 \%)$ of patients consumed strong analgesics dose in ward $\mathrm{A}$ in comparison to ward B (40.0\%). Analgesics and anesthetic besides having side effects that results in various postoperative behavioral complications (e.g., vomiting, headaches, nausea), are sometimes indispensable for some of the postoperative problems related to stress as they keep the patient calm and tranquil (Abbott and Abbott, 1995). This indicates a direct relation between high stress level and intake of analgesics. So for low analgesic consumption, it is important to keep the patients in a tranquil and serene atmosphere.

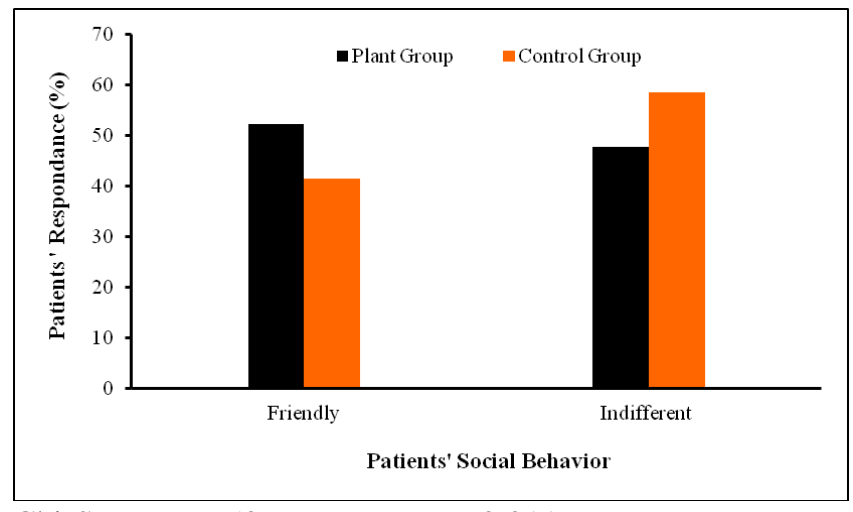

Chi-Square $=6.539$ $\mathrm{P}=0.011$

Figure 5. Evaluation of patient social behavior in the presence of indoor plants and flower arrangements.

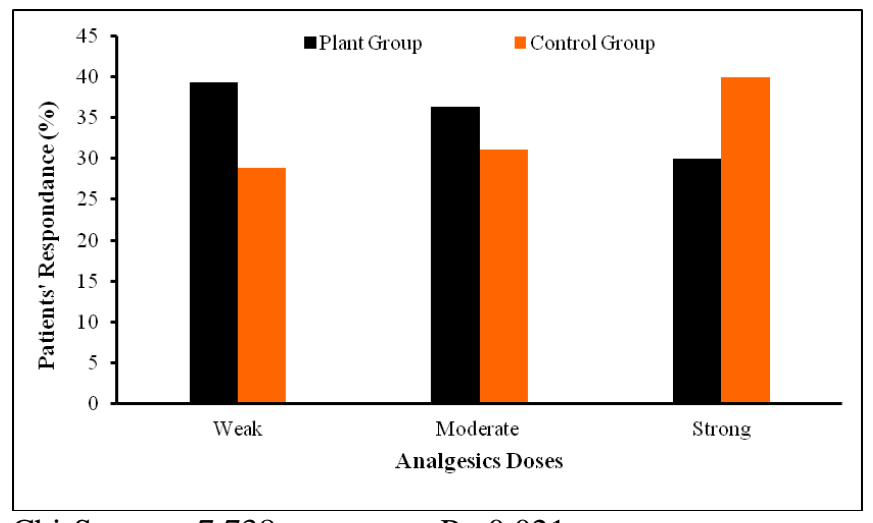

Chi-Square $=7.738$

$\mathrm{P}=0.021$

Figure 6. Impact of flowers arrangements and indoor plants on analgesics consumption of patients.

A study reported that patients exposed to nature scenes (with or without sounds) feel positive about their ailment and discomforts, reporting less pain and tenderness and display a higher pain tolerance while undergoing painful procedures (Schneider et al., 2003, 2004). Different studies reported 
patients exposed to the trees/green views suffered less severe pain, as evidenced by the fact they shifted faster from strong narcotic pain drugs to moderate strength analgesics. The studies further portrayed that patients who assigned to rooms with a view of nature after their surgery required fewer strong painkillers compared to those who were assigned a room with a view of a brick wall with no nature, suggesting that views of nature may act as a natural painkiller (Ulrich, 1984 and 2002).

Environmental assessment scales: General ward atmosphere was evaluated with the addition of foliage plants and flowers arrangement in regards to patient's responses. Environmental assessment scale includes few parameters such as ward cleanliness \& beautification, light quality in ward and patient's quality of stay in ward which would describes ward atmosphere in patient's views.

Ward beautification and its aesthetic value: Patient's opinions concerning general beautification and aesthetic value of wards are presented in Figure 7. The presence of flowers and foliage has developed a highly significant impact $(\mathrm{P} \leq 0.05)$ on the overall beautification and cleanliness of ward A as compare to ward B. An overwhelming percentage of patients $(68.9 \%)$ in ward $\mathrm{A}$ has described the ward as attractive and beautiful in comparison to ward B (26.7\%); whereas patients considering ward $\mathrm{B}$ as unattractive and dull were more $(59.3 \%)$ as compare to that in ward A $(18.5 \%)$. Furthermore, about $12.6 \%$ and $14.1 \%$ of patients give no response in ward $\mathrm{A}$ and $\mathrm{B}$ respectively. Plants and flowers always stimulate the aesthetic sense of human mind. Provision of more vegetation develops patient's connection with plants resulted in positive impact as well as improves the aesthetic value of the ward. Nature and living things tend to make most people feel happy and attract them (Kellert and Wilson, 1993; Maller et al., 2002).

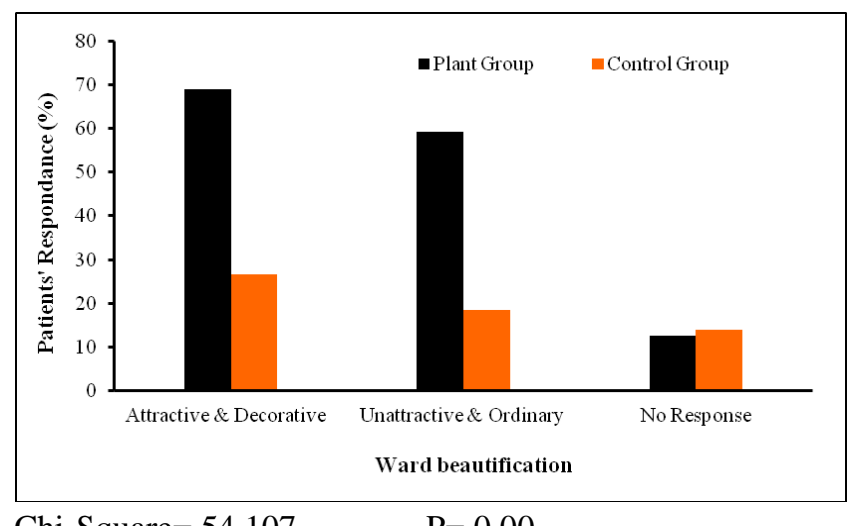

Chi-Square $=54.107 \quad \mathrm{P}=0.00$

Figure 7. Patient's view regarding ward beautification in the presence of indoor plants and flower arrangement.
Light quality in wards: Data about patient's opinion regarding light quality in both the wards are reported in Figure 8. A significant difference $(\mathrm{P} \leq 0.05)$ was recorded for preferred light quality by patients among the two comparing wards (A \& B). Patient's judging light as bright and vivid were more $(53.3 \%)$ in ward $\mathrm{A}$ than in ward $\mathrm{B}(38.4 \%)$; whereas $36.3 \%$ of patients in ward $A$ and $45.9 \%$ of patients in ward B reported light as dull and tedious in their wards. Patients with percentages of $10.4 \%$ and $15.6 \%$ in ward A \& ward B respectively give no response for the intervention. The green foliage of plants shines and buff when sunlight and normal room light falls of them, which creates a brighter and vivid environment and the patients respond for improved light quality and more brightened atmosphere. The presence of plants and flowers helps to brighten any human setting and creates an attractive and restorative atmosphere. So basically the difference was not in the light intensity in both the comparing wards, but actually reflection of sunlight and normal room light from green leaves creates an extra brightness and vividness, thus resulting in a more pleasant and cheering environments, and patients described it as a more brighter and lively indoor condition.

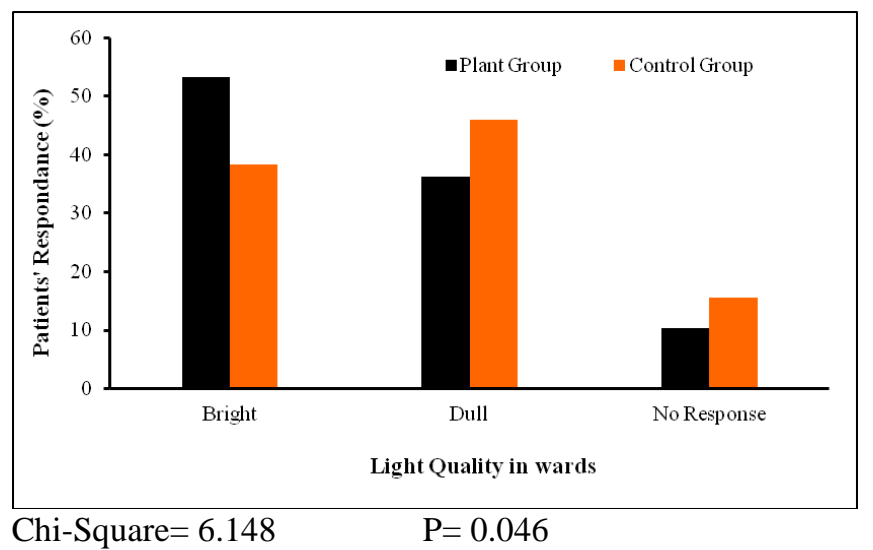

Figure 8. Impact of foliage plants and flower arrangement on the perception of patient regarding the light quality in wards.

Quality of stay in hospital : Data concerning the patient's overall quality of stay at the hospital wards is described in Figure 9. Impact of flowers and foliage on patients' quality of stay in ward A was significant $(\mathrm{P} \leq 0.05)$. Presence of flowers and foliage plants in ward $\mathrm{A}$, make the patients feel much calm and relaxed as compare to patients in ward B with no plants and flowers. Patients reporting for a calming and soothing stay in the hospital were higher $(57.0 \%)$ in ward A than in ward B (43.9\%); in the same manner, $33.3 \%$ of patients in ward A and $50.4 \%$ of patients in ward B portrayed an irritating and frustrating stay at the hospital respective. An almost equal percentage of patients from both the wards give no response in this regard. Plants and green surrounding 
prominently contributed to the psychological and social wellbeing of the residents, stimulated residents' senses, created positive emotions, and offered opportunity for rewarding activity (Rappe and Linden, 2004). Likewise, plants stimulate a greater variety of sight, touch, smell, taste, and hearing sensations (Caplan, 2006). Horticulture therapy (greenery and nature) mediates emotional, cognitive and/or sensory motor functional improvement, increased social participation, health, well-being and life satisfaction, thus improving the patients stay (Soderback et al., 2004).

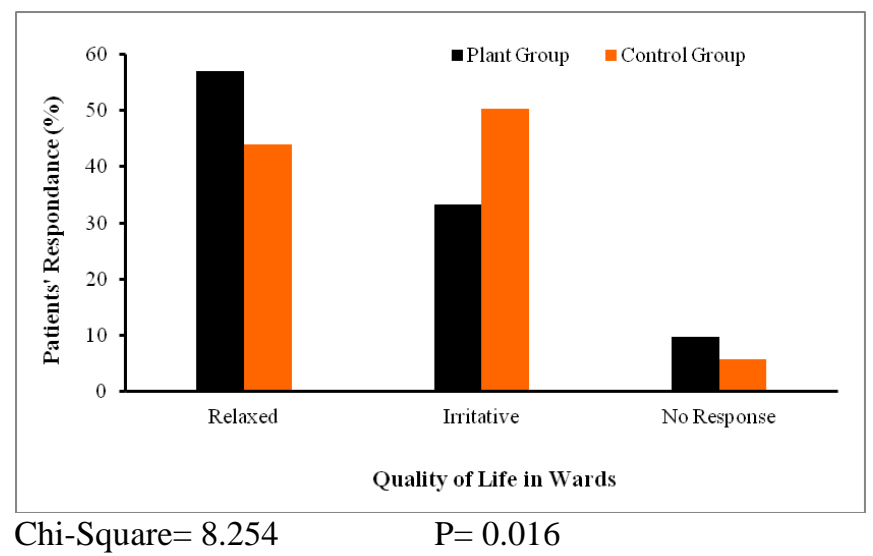

Figure 9. Impact of indoor foliage and flowers arrangement on the perception of patients regarding their quality of life in the hospital.

Patient's preferences for plants and flowers: Foliage plants and flowers arrangements were only provided to patients admitted in ward A. So patients' personal preferences for specific indoor plants and cut flowers on basis of their appearance and fragrance were asked only from patients in ward A.

In context of the graphs presented in Figures 10-12, it has been concluded that about $38.5 \%$ of patients preferred cut flowers in comparison to green and variegated foliage plants (Fig. 10). It's been observed that interacting with flowering plants appeared to have a stronger positive effect on human emotions than non-flowering plants (Yamane et al., 2004). Similarly, maximum percentage of patients $(45 \%)$ like rose cut flower for its appearance, overwhelming bloom and considerable amount of fragrance, followed by gladiolus preferred by $25 \%$ of patients' (Fig. 11). Rose due to its glooming and bright outlook and noticeable fragrance creates a positive distraction in patients mind and divert its mind from pain and anxiety towards brighter and healthy side of the surrounding. Rose being comparably less pronounced fragrant flower than other cut flowers used during the study, but its gloom and vibrant appearance can easily overcome this less fragrance factor and turn it as the most preferred cut flower for patients. Furthermore, more patients (48.9\%) like red color appearance in flowers and foliage plants, followed by yellow color (22.6\%) and then white color (14.8\%) (Fig. 12). Rose flower with red color is the most fascinating and preferred flower of people of Peshawar, Pakistan .

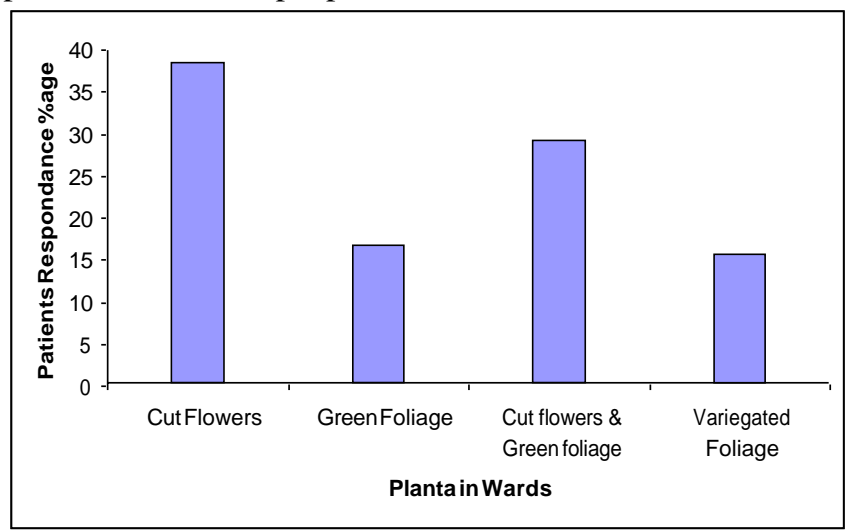

Figure 10. Patient preferences for various plants and flower arrangement types placed inside wards.

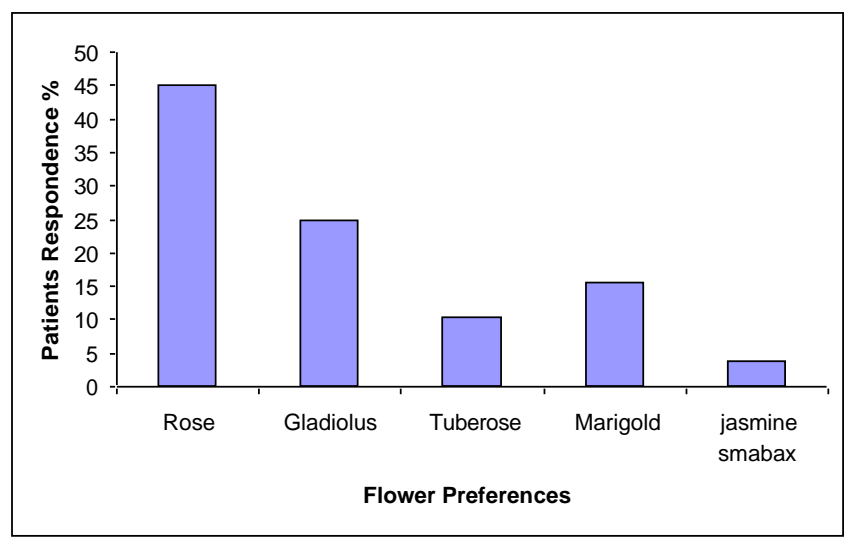

Figure 11. Patient preferences for different type of flower arrangement in relation to their appearance and fragrance.

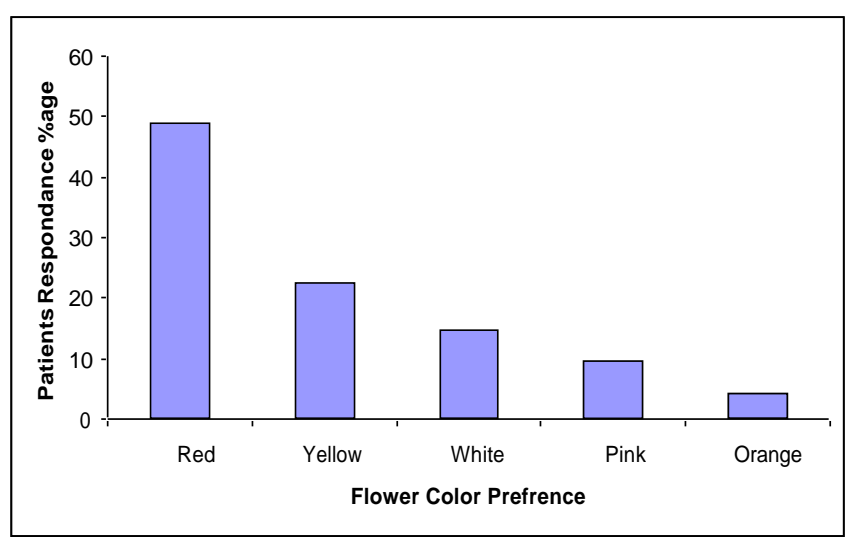

Figure 12. Patient preferences for different type of flower arrangement in relation to flower color. 
Color therapy is an area of holistic healing which uses color in an attempt to affect our mood, emotions, feelings and eventually our health. Colors are capable of influencing many aspects of our lives, including mental state and energy level, frame of mind, wellbeing, influence mood and cause psychological and cognitive responses (Kendra, 2012). As the most outrageous color, red represents power and strength to stimulate the body and mind and to increase blood circulation. It's thought to rouse and boost physical energy, strengthen willpower, vitality, increase blood circulation, clear congestion, overcoming negative thoughts, gives a sense of power, self-confidence, settled-ness, appetite stimulate and sense of power (Brian and Argisle, 2005). Beside the chromatheraphic effect of red cut rose flower, it's also considered as a symbol of love and harmony in our society and generally people holds a natural affection for rose flower, that's why it's known as 'king of flowers".

Conclusion: Foliage plants and flowers arrangement has helped to improve psychological and cognitive of patients by decreasing their anxiety, fatigue and tranquility levels. Environmental Assessment Scale responses indicated that patients were of the view that in the presence of indoor foliage plants and flowers, their rooms were more satisfying, relaxing, comfortable, colorful, calm and attractive as compared to those in the control group. So, therapeutic Horticulture is a non-pharmacological and noninvasive treatment approach and is medically beneficial and costeffective to patients as well as hospital administration.

\section{REFERENCES}

Abbott, J. and P. Abbott. 1995. Psychological and cardiovascular predictors of anesthesia induction, operative and postoperative complications in minor gynecological surgery. Brit. J. Clin. Psychol. 34:613-625. Aistars, J. 1987. Fatigue in the cancer patients: A conceptual approach to a 25-30. clinical problem. Oncol. Nurs. Forum 14:

Alexandria, V.A. 2009. Fresh flowers and plants promote innovation and ideas, $2^{\text {nd }} \mathrm{Ed}$. Southern Botanical, Inc. Dallas.

Berto, R. 2005. Exposure to restorative environment of patients helps to restore attentional capacity. J. Environ. Psychol. 25:249-259.

Brian, B. and B. Argisle. 2005. Light Years Ahead: The Illustrated Guide to Full Spectrum and Colored Light in Mindbody Healing, $2^{\text {nd }}$ Ed. Celestial Arts Press. California, USA.

Brown, J.R. 2001. Gardening for the senses. In: M.R. DeHart and J.R. Brow (eds.), National Garden Clubs: St. Louis, pp.179-182.
Cackowski, J.M. and J.L. Nasar. 2003. The restorative effects of roadside vegetation implication for automobile driver anger and frustration. Environ. Behav. 35:736-751.

Caplan, L. 2006. Gardening for the sense: The sensual garden. Purdue Extension Service, Purdue University, USA.

Carpman, J.R. and M.A. Grant. 1993. Design that cares: Planning health facilities for patients and visitors, $2^{\text {nd }} \mathrm{Ed}$. Chicago: American Hospital Publishing.

Chang, C.Y. and P.K. Chen. 2005. Human responses to window views and indoor plants in the workplace. HortScience 40:1354-1359.

Cho, H. 2002. The influence of social or task-oriented horticultural classes on adrenal immune axis responses, emotions, and common cold symptoms in female university students. Ph.D. Dissertation, Kansas State University, Manhattan, Kansas.

Diette, G.B., N. Lechtzin, E. Haponik, A. Devrotes and H.R. Rubin. 2003. Distraction therapy with nature sights and sounds reduces pain during flexible bronchoscopy: A complementary approach to routine analgesia. Chest.123: 941-948.

Fjeld, T. 2000. The effect of interior plantings on health and discomfort among workers and school children. HortTechnology 10: 46-52.

Grinde, B. and G.G. Patil. 2009. Does visual contact with nature impact on health and well-being? Int. J. Envir. Res. Public Health 6:2332-2343.

Hartig, T. 2004. Toward understanding the restorative environment as a health resource. In: Open space: People space. Engaging with the environment. OPENspace Research Centre, Edinburgh. Available online at http://www.openspace.eca.ac.uk/conference/proceeding s/summary/Hartig.htm.

Hartig, T., M. Barnes and C.C. Marcus. 1999. Conclusions and prospects. In: C.C. Marcus and M. Barnes (eds.), Healing gardens: Therapeutic benefits and design recommendations. John Wiley \& Sons: New York, pp:571-596.

Irvine, D.M., L. Vincent, N. Bubela, L. Thompson and J. Graydon. 1991. A critical appraisal of the research literature investigating fatigue in the individual with cancer. Cancer Nursing 14:188-199.

Johnson, M.H., G. Breakwell, W. Douglas and S. Humphries. 1998. The effects of imagery and sensory detection distractors on different measures of pain: How does distraction work? Brit. J. Clin. Psychol. 37:141-154.

Kaplan, R. 2001. The nature of the view from home: Psychological benefits. Environ. Behav. 33:507-542.

Kellert, S.R. and E.O.Wilson. 1993. The Biophilia Hypothesis. Washington, DC: Island Press.

Kendra, C. 2012. Color Psychology: How color impact moods, feelings and behaviors. An article on About. Com. Psychology. NewYork Times Company. 
Kuo, F.E. and W.C. Sullivan. 2001b. Aggression and violence in the inner city: Effects of environment via mental fatigue. Environ. Behav. 33:543-571.

Lautenbacher, S., P. Pauli, M. Zaudig, and N. Birbaumer. 1998. Attentional control of pain perception: The role of hypochondriasis. J. Psych. Res. 44: 251- 259.

Lewis, C.A. 2004. Human Health and Well-Being: The psychological, physiological and sociological effects of plants on people: Horticulture in human life, culture and environment. Acta Hort. 391:31-40.

Liu, M., E. Kim and R.H. Mattson. 2003. Physiological and emotional influences of cut flower arrangements and lavender fragrance on University students. J. Therap. Hort. 14:18-27.

Liu, M., R.H. Mattson and E. Kim. 2004. Influences of lavender fragrance and cut flower arrangements on cognitive performance. Int. J. Aromatherapy 14: 169174.

Lohr, V.I. and C.H. Pearson-Mims. 2000. Physical discomfort may be reduced in the presence of interior plants. HortTechnology 10: 53-58.

Maller, C., M. Townsend and P. Brown. 2002. Healthy parks healthy people. Melbourne: Deakin University and Parks Victoria.

Markland, D. and L. Hardy. 1993. Anxiety, relaxation, and anesthesia for day-case surgery. Brit. J. Clin. Psych. 32: 493-504.

Marucha, P.T., J.K. Kiecolt-Glaser and M. Favagehi. 1998. Muscular wound healing is impaired by examination stress. Psychosomatic Med. 60: 362-365.

Padgett, D.A., P.T. Marucha and J.F. Sheridan. 1998. The role of LGL/NK cells in surgery induced promotion of metastasis and its attenuation by morphine. Brain Behav. Immunity 8: 241-250.

Park, S.H. and H.M. Richard. 2009. Ornamental indoor plants in hospital rooms enhanced health outcomes of patients recovering from surgery. J. Alternat. Complem. Med. 9: 975-980.

Rappe, E. and L. Linden. 2004. Plants in health care environments: Experiences of the nursing personnel in homes for people with dementia. Acta Hort. 639:75-81.

Rodin, G. and K. Voshart. 1986. Depression in the medically ill: An overview. Amer. J. Psychiatry 143:696-705.

Schneider, S.M., M. Ellis, W.T. Coombs, E.L. Shonkwiler and L.C. Folsom. 2003. Virtual reality intervention for older women with breast cancer. Cyber Psych. Behav. 6:301-307.
Schneider, S.M., M. Prince-Paul, M.J. Allen, P. Silverman and D. Talaba. 2004. Virtual reality as a distraction intervention for women receiving chemotherapy. Oncol. Nursing Forum 31: 81-88.

Smith, D.J. 1998. Horticultural therapy: The garden benefits everyone. J. Psych. Nursing Mental Health Services 36: 14-21.

Soderbacka, I., S. Marianne and S. Elisabeth. 2004. Horticultural therapy: the 'healing garden' and gardening in rehabilitation measures at Danderyd hospital rehabilitation clinic, Sweden. Pediatric Rehabilitation 7: 245-260.

Tse, M.M.Y., J.K.F. Ng, J.W.Y. Chung and T.K.S. Wong. 2002a. The effect of visual stimuli on pain threshold and tolerance. J. Clin. Nursing 11: 462-469.

Tse, M.M.Y., J.K.F. Ng, J.W.Y. Chung and T.K.S. Wong. $2002 \mathrm{~b}$. The effect of visual stimulation via the eyeglass display and the perception of pain. Cyber psych. Behav. 5: 65-75.

Ulrich, R.S. 2002. Health benefits of gardens in hospitals. Paper for conference, Plants for People International Exhibition Floriade. Center for Health Systems and Design, Colleges of Architecture and Medicine Texas University College State, Texas.

Ulrich, R.S. 1984. View through a window may influence recovery from surgery. Sci. 224:420-421.

Ulrich, R.S. 1992. How design impacts wellness. Healthcare Forum J. 35:20-25.

Van den Berg, A.E., T. Hartig, and H. Staats. 2007. Preference for nature in urbanized societies: Stress, restoration, and the pursuit of sustainability. J. Social Issues 63: 79-96.

Whitehouse, S., J.W., Varni, M. Seid, C. Cooper-Marcus, M.J. Ensberg, J.J. Jacobs and R.S. Mehlenbeck. 2001. Evaluating a children's hospital garden environment: Utilization and consumer satisfaction. J. Environ. Psychol. 21: 301-314.

Wichrowski, M., J. Whiteson, F. Haas, A. Mola and M.J. Rey. 2005. Effect of horticultural therapy on mood and heart rate in patients participating in an inpatient cardiopulmonary rehabilitation program. J. Cardiopulm Rehabil. 25: 270-274.

Yamane, K., M. Kawashima, N. Fujishige and M. Yoshida. 2004. Effects of interior horticultural activities with potted plants on human physiological and emotional status. Acta Hort 639:37-43. 